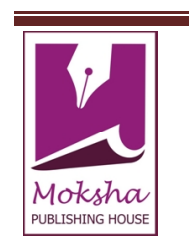

INTERNATIONAL RESEARCH JOURNAL OF PHARMACY

www.irjponline.com

ISSN $2230-8407$

Research Article

\title{
PHYSICOCHEMICAL AND PHYTOCHEMICAL INVESTIGATION OF THREE DIFFERENT SPECIES OF CURCUMA RHIZOME
}

Negi Richa Srivastava, Bindra Rattan Lal, Srivastava Vikas Kumar*, Kumar Dhirendra

R \& D Dept., Maharishi Ayurveda Products Pvt. Ltd., NSEZ, Noida, G. B. Nagar, (U. P.) India

Email: srivastava.vikas5@gmail.com

Article Received on: 15/01/13 Revised on: 07/02/13 Approved for publication: 11/03/13

DOI: $10.7897 / 2230-8407.04333$

IRJP is an official publication of Moksha Publishing House. Website: www.mokshaph.com

(C) All rights reserved.

\section{ABSTRACT}

The Zingiberaceae, the largest family in the Zingerabales, comprises nearly 50 genera and 1000 species and is pantropical concentrated mainly in the old world, chiefly in Indomalaysia. Members of the family yield species, dyes, perfumes, medicines and a number of ornamental species are cultivated for their ornamental flowers. Curcuma is one of the important 'Rasayana' drugs mentioned in Ayurveda.

In the present study three successive extractions of plant rhizomes viz. C. amada, C. malabarica and C. zedoaria were undertaken by using various solvent like alcohol, hydro-alcohol and water in their increasing polarity and the extracts thus obtained were subjected for their phytochemical analysis, followed by Thin Layer Chromatographic examination by optimizing the solvent system.

Keywords: Zingiberaceae, Rasayana, Curcumine, Cinnamaldehyde, Camphor.

\section{INTRODUCTION}

Plants have been a source of medicine for thousands of years, and phytochemicals continue to play an essential role in Indian culture and health care ${ }^{1}$. The origin of the effective drugs is given in our traditional texts with their formulations, in this view studies pertaining for testing of folklore medicinal plants for pharmacological studies has been taken up $^{2}$.

Most of the epidemiological studies established a link between phytochemicals and the range of biological activities that impart health benefits in human beings which dates back to Charaka Samhita. Scientific research supports the biological activity of many of the phytochemicals in isolation and combination. They were copiously used in Ayurveda and other traditional medicine. The groups of spices are considered to be the storehouse of active phytochemicals. Several groups of polyphenols (anthocyanins, proanthocyanidins, flavanones, isoflavones, resveratrol and ellagic acid), non-nutrient chemical and dietary constituents are currently used in the pharmaceutical industry. The various spices belonging to the genus Curcuma are well known for their multiple uses as medicines, cosmetics, dyes, flavourings and neutraceuticals ${ }^{3}$.

In developing countries, the practice of medicine still relies heavily on plant and herbal extracts for the treatment of human ailments and as a dietary supplements for health care. Dietary agents consist of a wide variety of biologically active compounds that are ubiquitous in plants, and many of them have been used as traditional medicines ${ }^{4,5,6}$. Traditionally, curcuma drugs called "Ukon" and "Gajutsu" in Japanese have been used in oketsu syndromes (caused by the obstruction of blood circulation) in Chinese medicine ${ }^{7}$.

Out of Curcuma family Curcuma longa is the most important species. There are extensive in-vitro and in-vivo investigations on turmeric extracts (ethanol, acetone, water and ethyl acetate extracts) or "pure" active "curcumine" powder over last half century. So the present study is focused on C. amada, C. malabarica and C. zedoaria. C. amada and C. zedoaria are distributed throughout India in the wild and cultivated forms; where as C. malabarica occur in south India ${ }^{8}$.
Curcuma amada Roxb., Zingiberaceae, (Mango-ginger) is a perennial herb cultivated as an annual with rhizomes having characteristic odour of raw mangoes. The rhizome finds extensive use in the indigenous systems of medicine ${ }^{9} . C$. amada is found the wild in parts of West Bengal, and is cultivated in Gujarat, Uttar Pradesh, Kerala, Karnataka, Tamil Nadu and the north-eastern states ${ }^{8}$.

Curcuma zedoaria a medicinal tuber plant belonging to this family, is a close relative of Curcuma longa. Various parts of Curcuma zedoaria are used in Ayurveda and other folk and tribal system of medicines ${ }^{10}$. Curcuma zedoaria is a constituent of a wide variety of ayurvedic preparations like Dasamularishtam, Valiya Rasnadi Kashayam, and so forth. The rhizome is used for curing stomach diseases, toothache, blood stagnation, leucoderma, tuberculosis, enlargement of spleen, and for promoting menstruation in traditional medicine in Asia ${ }^{10}$. Curcuma zedoaria (Christm) Roscoe has many components such as essential oils, oil-resin, therpenic compounds and other constituents, with a wide spectrum of biological properties. Presence of extract and the essential oil has cineol, camphene, alpha-pinene, camphor and other compounds this plant has been used in folk medicine, against digestive and gall bladder disorders, cough, hepatic disorders and halitosis, besides presenting anti-inflammatory and antimicrobial activities ${ }^{11}$. Extracts of Curcuma zedoaria and Curcuma malabarica tubers show antimicrobial activity ${ }^{12}$.

In the present study, physicochemical evaluation of three different species i.e. C. amada, C. malabarica and $C$. zedoaria has been later up. The extraction was carried out in three different solvent system i. e. alcoholic, hydro-alcoholic and water system and their comparison by TLC profiling.

\section{MATERIAL AND METHODS}

The rhizomes of three different species from $C$. amada, $C$. malabarica and $C$. zedoaria was collected from the different geographical region and used for the study.

\section{Reagent and chemicals}

All the reagent and chemicals used for the study were of analytical grade and purchased from authorized dealer of the company. 
Physico-chemical Evaluation

Physico-chemical parameters such as the total ash, acid insoluble ash, acid soluble ash, water insoluble ash, water soluble ash were determined as per standard methods. Considering the diversity of chemical nature and properties of contents of drugs, three different solvents water, alcohol and hydroalcohol were used for the determination of extractive values as per standard methods ${ }^{13-15}$. All determinations were carried in three experiments and the results were presented as mean \pm standard error of mean (SEM).

\section{Extraction process}

The preliminary phytochemical screening of the plant involves extraction of the plant material and identification of the plant active constituents.

\section{Preparation of extracts}

\section{Method of extraction}

Continuous hot percolation process by using Soxhlet apparatus

\section{Materials}

1. Soxhlet apparatus

2. Alcohol

3. Distilled water

4. Shade dried coarse powder of rhizome of different sp. of Curcuma.

\section{METHODS}

\section{Preparation of extract}

The shade dried powdered material (60 mesh, 100g) of each species was extracted with alcohol, hydroalcohol (30:70) and water. The extracts obtained was concentrated under vacuum $(-760 \mathrm{mmHg})$ and stored in a desiccator. The weight of the each extract is given in tablet.

\section{Development Method}

One dimensional ascending method by using standard protocol was followed. Different extracts were applied $1 \mathrm{~cm}$ above from the base of the TLC plates. Development was done using petroleum ether: ethyl acetate (7:3) solvent systems.

\section{Visualization}

Developments of chromatograms were carried out by spraying anisaldehyde- $\mathrm{H}_{2} \mathrm{SO}_{4}$ reagent followed by gentle heating at $105^{\circ} \mathrm{C}$ till the spots were developed ${ }^{16,17}$.

\section{Documentation}

After visualization as mentioned above different spots were detected. The $\mathrm{Rf}$ values of those spots were recorded carefully and the chromatograms were documented by photography and UV light.

\section{Phytochemical Screening}

The TLC profile from the various extract demonstrates the presence of cinnamaldehyde and camphor. The details of Rf values are given in table-3.

The detail about phytochemical constituents present in various extracts is summarized in table- 4 .

\section{Phytochemical Evaluation}

\section{Test for Steroid}

To $2 \mathrm{ml}$ of extract add $2 \mathrm{ml}$ chloroform and $2 \mathrm{ml}$ conc. $\mathrm{H}_{2} \mathrm{SO}_{4}$. Shake well, chloroform 1 layer appear red and acid layer show greenish yellow florescence ${ }^{18}$

\section{Test for Glycoside}

To the solution of the extract add glacial acetic acid, few drops $5 \%$ ferric chloride and concentrated sulphuric acid are added, and observed for a reddish brown coloration at the junction of two layers and the bluish green color in the upper layer $^{19}$.

\section{Test for Flavanoid}

To $4 \mathrm{ml}$ of extract add $1.5 \mathrm{ml}$ of $50 \%$ methanol solution. The solution was warmed and metal magnesium was added. To this solution, 5-6 drops of concentrated hydrochloric acid was added, red color was observed for flavonoids and orange color for flavones ${ }^{20}$.

\section{Test for Alkaloid}

To $0.5 \mathrm{~g}$ of each extract adds $5 \mathrm{ml}$ of $1 \%$ aqueous hydrochloric acid and kept in water bath; $1 \mathrm{ml}$ of the Filtrates is to be treated with Mayer's reagent (Potassium Mercuric Iodide). Formation of a yellow colored precipitate indicates the presence of alkaloids.

\section{Test for Tannin}

To $0.5 \mathrm{ml}$ of extract solution, $1 \mathrm{ml}$ of water and 1-2 drops of ferric chloride solution was added. Blue color was observed for gallic tannins and green black for catecholic tannins ${ }^{19}$.

\section{Test for Saponin}

To $1 \mathrm{ml}$ extract add $2 \mathrm{ml}$ distilled water and shake it. Persistent foam was observed.

Table 1: Physicochemical Properties of Curcuma sp.

\begin{tabular}{|c|c|c|c|}
\hline Quantitative standards & C. amada & C. malbarica & C. zedoaria \\
\hline Total Ash Value (in \%w/w) & $5.28 \pm 0.29$ & $6.09 \pm 0.22$ & $7.50 \pm 0.16$ \\
\hline Acid Insoluble Ash (in \%w/w) & $0.39 \pm 0.18$ & $0.39 \pm 0.18$ & $0.55 \pm 0.15$ \\
\hline Aqueous soluble Ash (in \%w/w) & $10.67 \pm 0.32$ & $15.89 \pm 0.22$ & $19.61 \pm 0.73$ \\
\hline Moisture content (in \%w/w) & $7.96 \pm 0.35$ & $11.02 \pm 0.18$ & $5.35 \pm 0.94$ \\
\hline
\end{tabular}

Table 2: Percentage yield in successive solvent extraction

\begin{tabular}{|c|c|c|c|}
\hline Extracts & C. amada & C. malbarica & C. zedoaria \\
\hline Water soluble extractive & $30.48 \%$ & $10.97 \%$ & $5.96 \%$ \\
\hline Alcohol soluble extractive & $6.54 \%$ & $9.49 \%$ & $7.17 \%$ \\
\hline Hydro-alcohol soluble extractive & $6.51 \%$ & $10.59 \%$ & $14.11 \%$ \\
\hline
\end{tabular}


Negi Richa Srivastava et al. Int. Res. J. Pharm. 2013, 4 (3)

Table 3: TLC analysis of extracts of plant with their Rf values

\begin{tabular}{|c|c|c|c|c|c|}
\hline Curcuma Sp. & Plate No. & Extract & Curcumine & Cinnamaldehyde & Camphor \\
\hline \multirow[t]{3}{*}{ C. Amada } & Plate a & $0.53,0.64,0.79$ & - & 0.37 & 0.53 \\
\hline & Plate b & $0.51,0.59,0.73,0.82$ & - & 0.35 & 0.56 \\
\hline & Plate $\mathrm{c}$ & $0.56,0.70,0.79$ & - & 0.38 & 0.55 \\
\hline \multirow[t]{3}{*}{ C. malbarica } & Plate d & $0.39,0.64,0.74$ & - & 0.33 & 0.52 \\
\hline & Plate e & $0.09,0.56,0.72$ & - & 0.32 & 0.54 \\
\hline & Plate $\mathrm{f}$ & $0.55,0.61,0.71,0.80$ & - & 0.32 & 0.57 \\
\hline \multirow[t]{3}{*}{ C. zedoaria } & Plate $g$ & $0.22,0.32,0.38$ & - & 0.37 & 0.56 \\
\hline & Plate h & $0.61,0.74,0.80$ & - & 0.39 & 0.59 \\
\hline & Plate i & $0.26,0.52,0.67$ & - & 0.36 & 0.55 \\
\hline
\end{tabular}

Table 4: Phytochemical constituents present in various extracts

\begin{tabular}{|c|c|c|c|}
\hline Phytochemical constituents & Curcuma amada & Curcuma malbarica & Curcuma zedoaria \\
\hline Steroids/Triterpenoids & + & + & + \\
\hline Glycoside & + & + & - \\
\hline Flavonoids & + & - & + \\
\hline Alkaloids & - & - & - \\
\hline Tannins & - & - & - \\
\hline Saponins & - & - & \\
\hline
\end{tabular}
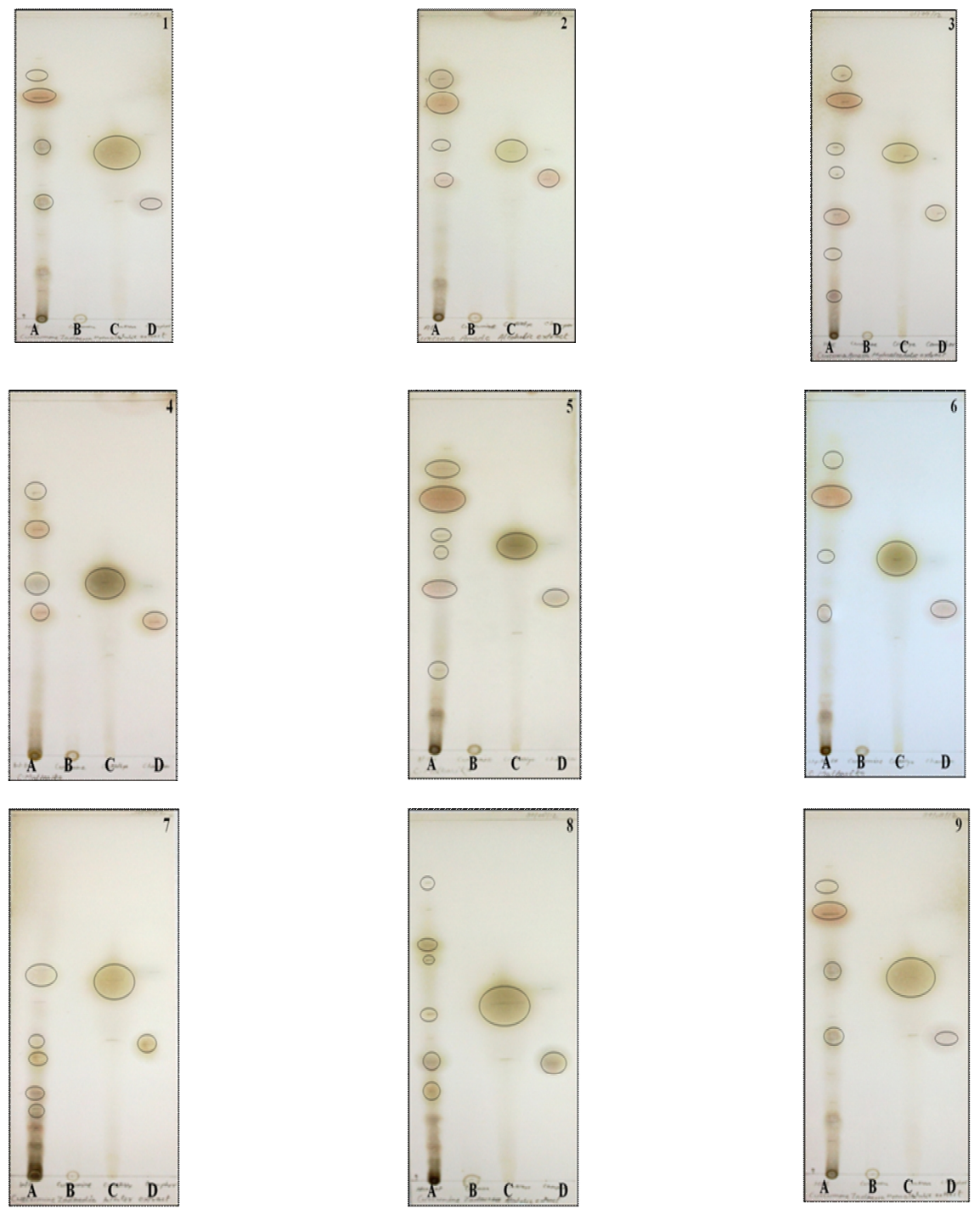

Figure 3: TLC finger printing profile of Curcuma sp.

(Spot A- extract, B-Curumine standard, C-Cinnamaldehyde standard, D-Camphor standard)

1. TLC profile of water soluble extractive of $C$. amada, 2.TLC profile of alcohol soluble extractive of $C$. amada, 3.TLC profile of hydro-alcohol soluble extractive of $C$. amada, 4.TLC profile water soluble extractive of $C$. malabarica, 5.TLC profile of alcohol soluble extractive of $C$. malabarica,

6.TLC profile of hydro-alcohol soluble extractive of C. malabarica, 7.TLC profile water soluble extractive of $C$. zedoaria,

8.TLC profile of alcohol soluble extractive of C. zedoaria, 9.TLC profile of hydro-alcohol soluble extractive of $C$. zedoaria 


\section{RESULTS}

Physico-chemical Evaluations

The physicochemical studies of rhizome of Curcuma Sp. are summarized in table-1.

The percentage yield in successive solvent extraction is summarized in table- 2 .

\section{DISCUSSION}

The physical evaluation furnished different ash values, extractive values in three different species of Curcuma. Total ash, acid insoluble ash and water soluble ash values were also determined.

Three different solvents viz. Water, alcohol, hydro-alcohol soluble was selected for extractive values study. This showed water soluble extractive value was found to be more than alcohol soluble extractive value however it was less than hydro-alcohol soluble extractive value.

The TLC analysis was performed by usual technique using the optimized solvent systems specific for the various classes of compound. Detecting reagent was used to visualize the chromatograms. Thus a variety of standardization parameters viz. physico-chemical, phytochemical and chromatographical parameters were studied and a data was generated to ensure the quality of plant material for future reference.

\section{CONCLUSION}

The methanolic extracts of the studied plants showed the presence of bioactive compounds in all the three species, amongst the three Curcuma amada and Curcuma malabarica have maximum bioactive compounds. Thus these two are pharmacologically and medicinally more important than Curcuma zedoaria which has been discussed.

The TLC profile of the three different extracts also put the information that cinnamaldehyde and camphor is present in all the three species of Curcuma but curcumine is totally absent or in such a less quantity to detect by TLC finger printing.

\section{ACKNOWLEDGMENT}

The author thanks Mr. Sanjay Srivastava (Executive Director) of Maharishi Ayurveda Products Pvt. Ltd. for giving his valuable support and facilities to conduct this research work.

\section{REFERENCES}

1. Aggarwal BB, Kumar A, Bharti AC. Anticancer potential of curcumin: preclinical and clinical studies. Anticancer Research. 2003; 23(1A):363-98.

2. Wealth of India. 2001. A dictionary of Indian Raw Materials and Industrial Products, NISCOM (CSIR), New Delhi, 262- 264.
3. Policegoudra RS, Aradhya SM, Singh L. Mango ginger (Curcuma amada Roxb.)-a promising spice for phytochemicals and biological activities. Journal of Bioscience. 2011; 36(4):739-48. http://dx.doi.org/ 10.1007/s12038-011-9106-1

4. Aggarwal B B, Shishodia Shishir, Suppression of the Nuclear Factor-k B Activation Pathway by Spice-Derived Phytochemicals: Reasoning and Seasoning, Annals of the New York Academy of Sciences, 2004; 1030: 434-441. http://dx.doi.org/10.1196/annals. 1329.054

5. Aggarwal B B, Shishodia Shishir, Molecular targets of dietary agents for prevention and therapy of cancer. Biochemical Pharmacology, 2006; 71: 1397-1421. http://dx.doi.org/10.1016/j.bcp.2006.02.009

6. Singhal $\mathrm{M} \mathrm{K}$, Jungles: rich sources of medicinal plants, Natural Product Radiance, 2004; 3: 203,

7. Li S Z, Ben-cao gung-mu, in Jiangxi (ed) The People's Health Pub, House, Beijing, China, 1977; 2: 880- 885,

8. Velayudhan KC, Muralidharan VK, Amalraj VA, Gautam PL, Mandal S and Kumar D 1999 Curcuma genetic resources. Scientific monograph No.4. National Bureau of Plant Genetic Resources Regional Station, Thrissur, Kerala, India, 1-27.

9. Mridula KR, Jayachandran BK, Quality of mango-ginger (curcuma amada roxb.) As influenced by Mineral nutrition. Journal of Tropical Agriculture. 2001; 39: 182-183.

10. Saikia N, Nath S. C., Ethnobotanical observations of some species of the genus Curcuma L. growing in Assam, Journal of Economic and Taxonomic Botany, 2003; 27: 430-433.

11. Nicoletti MA, Bugno A, Orsine EMA, Zenebon O, Estudo da atividade antimicrobiana do extrato fluido da Curcuma zedoaria (Christm) Roscoe - Determinação da concentração minima inibitória. Rev. Bras. Farm. 2003; 84(2): 39-41.

12. Wilson B, Abraham G, Manju VS, Mathew M, Vimala B, Sundaresan $\mathrm{S}$ et al. Antimicrobial activity of Curcuma zedoaria and Curcuma malabarica tubers. J ournal of Ethnopharmacol. 2005; 99(1):147-51. http://dx.doi.org/10.1016/j.jep.2005.02.004

13. Mukherjee P K. Quality Control of Herbal Drugs. Bussiness Horizons. New Delhi. 2002; 164-171.

14. Kokate CK. Practical Pharmacognosy; Vallabh Prakashan, New Delhi. 1994; 107-111.

15. Khandelwal KR. Practical Pharmacognosy. Techniques and Experiments. Nirali Prakashan, Pune, 2005; 149-153.

16. Wagner H, bladt S. Plant Drug analysis- A thin layer chromatography atlas. Thomson Press (India) Ltd. 275-278.

17. Hajons Mw, Sharma J, Kowaska J. Thin layer chromatography in phytochemistry. CRC press New York, 2008; 255-853.

18. Kannan D, Mehra RS, Dubey S, Tiwari S, Maheshwari U, Bisht VS. Evaluation Of Phytochemical Constituents, Antibacterial Activities, Cytopathic And Cytotoxic Effects Of Extracts Of Tylophora Indica, Curcuma Amada And Urtica Dioica Of Recent Advances In Applied Sciences (JRAAS), 2013;28:01-11.

19. Siddiqui AA, Ali M. Practical Pharmaceutical chemistry. CBS Publishers and Distributors, New Delhi, 1997; 126-131.

20. Iyengar MA, Study of Crude Drugs, Manipal Power Press, Manipal, India. 8th edition 1995; 2 - 7.

Cite this article as:

Negi Richa Srivastava, Bindra Rattan Lal, Srivastava Vikas Kumar, Kumar Dhirendra. Physicochemical and phytochemical investigation of three different species of Curcuma rhizome. Int. Res. J. Pharm. 2013; 4(3):163166 